\title{
Serve analyses of elite European table tennis matches
}

\author{
Zoran Djokic', Ivan Malagoli Lanzoni², Michail Katsikadelis ${ }^{3}$, Gunter Straub ${ }^{4}$ \\ 'Faculty of Sport and Tourism, University EDUCONS - Novi Sad, Serbia \\ ${ }^{2}$ School of Pharmacy, Biotechnology, and Sport Sciences. University of Bologna, Italy \\ ${ }^{3}$ School of Physical Education and Sport Science, Democritus University of Thrace, \\ Greece \\ ${ }^{4}$ Association of German Table Tennis Coaches, Germany
}

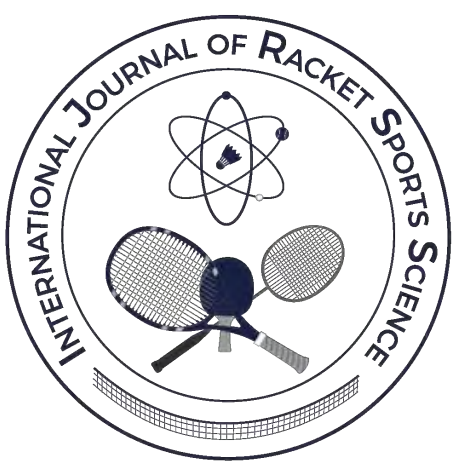

\section{Abstract}

The purpose of this study was to analyze the serve activities of elite European table tennis players. Twenty matches (78 games, 1466 points) of semifinal and final German League and Europe TOP 16 in men's (in the top 30 of ETTU Rank list) were analyzed. Differences in serving activities (type, stroke type, outcome and placement) were analyzed according results outcome of match, game, point, phase of the game and type of games.

Results showed that forehand short serve prevailed (76.9\%) instead other types of serve, mostly placed in the middle of the table on the opponent's backhand side. Percentage of point won directly with serve was $11.6 \%$, points won with $3^{\text {rd }}$ stroke $-22.4 \%$ and points won with $5^{\text {th }}$ stroke after serve $(10.9 \%)$. Lost points after serve mostly were after $3^{\text {rd }}$ stroke $(25.0 \%)$ and after $5^{\text {th }}$ stroke $(22.4 \%)$ and serve errors were noted in $1.5 \%$ of all analyzed points. In the $3^{\text {rd }}$ phase of the game serve points were won mostly with $3^{\text {rd }}$ and $5^{\text {th }}$ stroke instead previous phases of the game.

Results of Pearson's chi-squared test showed an association between match outcomes and serve type and outcome, serve type and outcome considering phase of the game and different type of games with serve type, outcome and placing zones.

Keywords: Activity Analyses, Notational Analyses, Player Performance

Correspondence author: Zoran Djokic

E-mail: zoran.djokic@tims.edu.rs

Cite this article as:

Djokic, Z., Malagoli Lanzoni, I., Katsikadelis, M., \& Straub, G. (2020). Serve analyses of elite European table tennis matches. International Journal of Racket Sports Science, 2(1), 1-8. 


\section{Introduction}

Table tennis is a complex sport with a large number of different types of strokes, which become even more specialized or individualized by the type of execution, the intensity, and the tactical goal (Tepper, 2003), However, the serve in table tennis affects the whole rally. The serve in table tennis is the strokes that puts the ball in play and is often referred to as one of the most important strokes in the game, influencing one's scoring or losing tendency. In general, players should take maximum advantage of a service in order to score and this is regarded as the most important challenge for them (Molodzoff, 2008; Geske \& Muller, 2010).

High performance table tennis requires observation and measurement to improve knowledge of performance, application of new knowledge to enhance performance (Hughes, Cooper, \& Nevill, 2004), so collecting data of strategy and tactics is important, and can help coaches and players to better understand and prepare a strategy for the match (O’Donoghue, 2004; Padulo et al., 2016).

Serve activities already were reported as important indicators of performance in high-ranking table tennis players (Djokic, 2002a, 2002b, 2003; Katsikadelis, Pilianidis, \& Mantzouranis, 2013; Zhang, Liu, Hu, \& Liu, 2013; Malagoli Lanzoni, Di Michele, \& Merni, 2014; Tamaki, Yoshida, \& Yamada, 2017; Fuchs et al., 2018; Zhang, Zhou, \& Yang, 2018).

Previous research has shown that $80 \%$ of rallies in the table tennis matches ends at the fifth stroke, and even if the rally continues, one player is usually in a winning position at that same stroke (McAfee, 2009). Besides, a more recent study confirmed that rallies become shorter (Leite et al., 2017; Djokic, Munivrana, \& Levajac, 2016a, 2016b). The application of the most recent service rules as well as the use of new rubbers and plastic balls seem to decrease the efficacy of serve resulting in the shortening of the match (Djokic et al., 2019).

Considering all this as well as the serve impact on the game, there is strong need for permanent analyses and monitoring.
The aim of this study was to analyze the serve activities of elite European table tennis players.

\section{Material and methods}

\section{Data sample}

Twenty matches (78 games, 1435 points) of semifinal and final German League (season 2018/19 and Europe TOP 16 (2018) in men's competition were analyzed. All players were in the top 30 of ETTU Rank list.

\section{Variables}

Performance indicators measured to provide information about the serve activities were:

Serve type:

1) FSHOSE - Forehand short serve (serve that, if allowed, ball would bounce twice on the far side of the table).

2) FLONSE - Forehand long serve (serve, with the second bounce off the table)

3) BSHOSE - Backhand short serve

4) BLONSE - Backhand long serve Serve outcome:

5) SERDIR - Serve direct point

6) SER3WN - Serve point won after $3^{\text {rd }}$ stroke

7) SER5WN - Serve point won after $5^{\text {th }}$ stroke

8) SER7WN - Serve point won after $7^{\text {th }}$ stroke

9) SER3LS - Serve lost point after $3^{\text {rd }}$ stroke

10) SER5LS - Serve lost point after $5^{\text {th }}$ stroke

11) SERROR - Serve error

Serve placement (Djokic, 2002b):

12) SOUTFH - Outside forehand zone

13) SMIDFH - Middle forehand zone

14) SMIDBH - Middle backhand zone

15) SOUTBH - Outside backhand zone

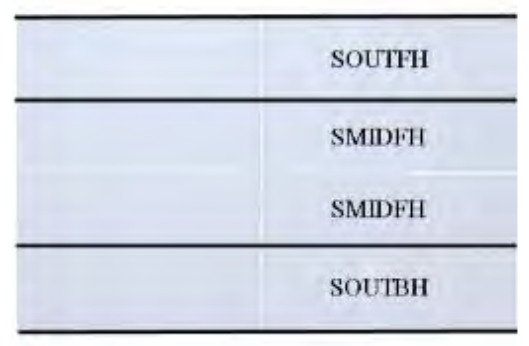

Figure 1. Serve placement zones 
Differences in serving activities (type, outcome and placement) were analyzed according to the final results outcome of match, game and point. Also, we considered 3 score periods (phases) in game: from 0 to 4 points as the first phase (e.g. till 4:3), from 5 to 8 the second phase (e.g. from 5:4) and 8 to 11 the third phase (e.g. from 8:5) of the game with the aim to see does the serve activities differ in different part of the game. At the end, according to the game result we analyzed serve activities in three type of games: balanced (2 difference points (e.g. 11:9, 12:10), $\mathrm{N}=$ 464), unbalanced (3-5 difference points (e.g. 11:6$11: 8), \mathrm{N}=826$ ) and very unbalanced ( 6 and more difference points (e.g. 11:0-11:5), $\mathrm{N}=174$ ).

\section{Procedure}

Data were collected by videos of matches available on the official DTTB and ITTF website. The video material allowed the observers during the video analysis to clearly see the players, the table, and the playing area, which allowed a reliable verification of all events during the match. The observer analysed video of the matches in real speed, but in case of certain inconsistencies, they were re-wound and seen in slow motion $(0.2 \mathrm{X})$. Kinovea, a free $2 \mathrm{D}$ motion analysis software (player) under GPLv2 license was used. All the data were registered in the specially prepared templates for the analysis of every match (by hand on paper), in which all the analysed variables were coded and after that, the data were input to a Microsoft Excel spreadsheet.

\section{Reliability}

In order to ensure a quality of reliability (O'Donoghue \& Mayes, 2013), the matches were evaluated by means of intra- and inter-observers. For this research, two expert table tennis coaches were engaged for the role of observers. The intra- and inter-observer reliability is based on the analysis and re-analysis of 20 games randomly selected. Krippendorff's Alpha was calculated to assess data collection reliability (Krippendorff, 2004). The intraobserver reliability analysis showed an Alpha value of 0.995. Inter-observer reliability was assessed reanalysing all the matches by the second analyst.

\section{Statistical analyses}

Descriptive statistical parameters (frequencies and percentages) were calculated for all analyzed samples with a consideration of result outcome (winners/losers). A Pearsoń s chi-square test of independence was performed to examine the relation between serve activities and winning matches, with a level of significance of $(a=0.05)$. All the data were analyzed using SPSS 20.0 (IBM Corporation, USA).

\section{Results}

Results showed that short forehand serve is the most used kind of service. Complete results of analyses of serve type are shown in Table 1.

Table 1.

Results of analysis of serve type of all sample and according result outcome (winners/losers)

ALL SAMPLE WINNERS

LOSERS

\begin{tabular}{lcccccc}
\hline & Frequency & $\%$ & Frequency & $\%$ & Frequency & $\%$ \\
FSHOSE & 1126 & 76.9 & 584 & 80.3 & 542 & 74.8 \\
FLONSE & 254 & 17.3 & 102 & 14.4 & 152 & 20.3 \\
BSHOSE & 62 & 4.2 & 32 & 4.6 & 30 & 4.5 \\
BLONSE & 4 & 0.3 & 2 & 0.7 & 2 & 0.4
\end{tabular}


Based on the results of chi-square test we can state that there was a significant association between winning the match and serve type $\mathrm{X} 2(2, \mathrm{~N}=1466)=$ 11.685, $\mathrm{p}<0.20$ ).

The serve outcome in analyzed matches showed that most points were won with the $3^{\text {rd }}$ ball after serving and directly with serve, while most often points were lost after $3^{\text {rd }}$ and $5^{\text {th }}$ stroke. Results of analyses of serve outcome are shown in Table 2.

Table 2.

Results of analysis of serve outcome of all sample and according result outcome (winners/losers)

\begin{tabular}{llcccccc} 
& & ALL SAMPLE & \multicolumn{3}{c}{ WINNERS } & \multicolumn{2}{c}{ LOSERS } \\
& & Frequency & $\%$ & Frequency & $\%$ & Frequency & $\%$ \\
\hline \multirow{3}{*}{ Won points } & SERDIR & 170 & 11.6 & 94 & 12.9 & 76 & 10.3 \\
& SER3WN & 328 & 22.4 & 170 & 23.3 & 158 & 21.5 \\
& SER5WN & 160 & 10.9 & 92 & 12.6 & 68 & 9.2 \\
& SER7WN & 90 & 6.1 & 60 & 8.2 & 30 & 4.1 \\
& Total & 748 & 51.1 & 416 & 57.1 & 332 & 45.1 \\
\cline { 2 - 8 } Lost points & SER3LS & 366 & 25.0 & 176 & 24.1 & 190 & 25.8 \\
& SER5LS & 328 & 22.4 & 126 & 17.3 & 202 & 27.4 \\
& SERROR & 22 & 1.5 & 10 & 1.4 & 12 & 1.6 \\
& Total & 716 & 48.9 & 312 & 42.9 & 404 & 54.9 \\
\hline
\end{tabular}

Table 3.

Results of analysis of serve placement of all sample and according result outcome (winners/losers)

ALL SAMPLE

\begin{tabular}{lcccccc}
\hline & Frequency & $\%$ & Frequency & $\%$ & Frequency & $\%$ \\
SOUTFH & 186 & 12.8 & 104 & 14.4 & 82 & 11.3 \\
SMIDFH & 306 & 21.1 & 140 & 19.4 & 166 & 22.9 \\
SMIDBH & 730 & 50.4 & 354 & 49.3 & 376 & 51.8 \\
SOUTBH & 224 & 15.5 & 122 & 16.9 & 102 & 14.0 \\
\hline
\end{tabular}

Based on the results of chi-square test we can state the that there was a significant association between winning the match and serve outcome, X2(2, $\mathrm{N}=1466)=34.229, \mathrm{p}<.000)$.

Most of the points after serve were finished after 3-5 stroke, and winners has a better percentage of winning points on serve directly and after $3^{\text {rd }}$ and $5^{\text {th }}$ stroke.

The most used zone on the opponent's side of the table where serve were placed was middle, more in backhand side. Results of analyses of serve placement are shown in Table 3.

There was no significant association between winning the match and serve placement.

Analyzing serve activities and outcome instead of the phase of the game, it is noted that in last phase most points were won with $3^{\text {rd }}$ and $5^{\text {th }}$ stroke. Besides, involving the backhand serve was noted in $2^{\text {nd }}$ and $3^{\text {rd }}$ phase (Table 4 ). 
Table 4.

Results of analysis of serve type and outcome in different phases of the match of all sample

\begin{tabular}{|c|c|c|c|c|}
\hline & & $1^{\text {st }}$ PHASE & $2^{\text {nd }}$ PHASE & $3^{\text {rd }}$ PHASE \\
\hline \multirow[t]{5}{*}{ Serve type } & FSHOSE & 79.9 & 73.9 & 77.5 \\
\hline & FLONSE & 17.6 & 19.9 & 16.3 \\
\hline & BSHOSE & 2.5 & 5.8 & 5.7 \\
\hline & BLONSE & 0.0 & 0.4 & 0.5 \\
\hline & Total & 100.0 & 100.0 & 100.0 \\
\hline \multirow[t]{4}{*}{ Won points $\%$} & SERDIR & 10.5 & 13.5 & 10.6 \\
\hline & SER3WN & 21.0 & 21.0 & 25.8 \\
\hline & SER5WN & 10.5 & 9.0 & 13.8 \\
\hline & SER7WN & 4.4 & 7.0 & 6.9 \\
\hline \multirow[t]{4}{*}{ Lost points \% } & SER3LS & 27.0 & 24.0 & 24.0 \\
\hline & SER5LS & 25.0 & 24.0 & 17.5 \\
\hline & SERROR & 1.6 & 1.5 & 1.4 \\
\hline & Total & 100.0 & 100.0 & 100.0 \\
\hline
\end{tabular}

Table 5.

Results of analysis of serve activities for won/lost points

WON POINTS

LOST POINTS

\begin{tabular}{llcccc} 
& & Frequency & $\%$ & Frequency & $\%$ \\
\hline Serve type & FSHOSE & 584 & 78.1 & 542 & 77.8 \\
& FLONSE & 130 & 17.3 & 124 & 17.3 \\
& BSHOSE & 32 & 4.3 & 30 & 4.2 \\
& BLONSE & 2 & 0.3 & 2 & 0.7 \\
& Total & 748 & 100.0 & 698 & 100.0 \\
\hline Won points & SERDIR & 170 & 22.8 & & \\
& SER3WN & 328 & 44.0 & & \\
& SER5WN & 158 & 21.2 & & \\
Lest points & SER7WN & 90 & 12.0 & & \\
& SER3LS & & & 366 & 51.1 \\
& SER5LS & & & 328 & 45.7 \\
& SERROR & & & 22 & 3.2 \\
& Total & 746 & 100.0 & 716 & 100.0 \\
\hline Serve placement & SOUTFH & 90 & 12.0 & 96 & 13.7 \\
& SMIDFH & 148 & 19.8 & 158 & 22.7 \\
& SMIDBH & 396 & 52.9 & 334 & 47.7 \\
& SOUTBH & 114 & 15.3 & 110 & 15.9 \\
& Total & 1494 & 100.0 & 1414 & 100.0 \\
\hline
\end{tabular}

There was a significant association between phase of the game and serve type, $\mathrm{X} 2(2, \mathrm{~N}=1464)=$
$16.669, \mathrm{p}<.034)$ and serve outcome $\mathrm{X} 2(2, \mathrm{~N}=1464)$ $=22.591, \mathrm{p}<.031)$ 
The analyses of all won and lost points were done from the aspects of serve type, outcome, placement and type. Results of analyses are shown in Table 5.

Won points are mostly in the $3^{\text {rd }}$ rally $(44.0 \%)$ and $5^{\text {th }}$ rally $(21.2 \%)$, while lost in the $3^{\text {rd }}(51.0 \%)$ and $5^{\text {th }}$ (45.7\%).

Considering type of game, we analyzed differences in serve activities between balanced and unbalanced games (very unbalanced were excluded because they didn't represent real game situation considering result. There was noted a significant association between serve type, X2 $(2, \mathrm{~N}=1290)=12,588, \mathrm{p}<$ $.013)$, serve outcome, $\mathrm{X} 2(2, \mathrm{~N}=1290)=14,794, \mathrm{p}<$ $.022)$ and serve placement, $\mathrm{X} 2(2, \mathrm{~N}=1290)=$ $81,362, \mathrm{p}<.000)$. In balanced games players used more backhand serves, more points were won in $3^{\text {rd }}$ stroke, fewer lost after $3^{\text {rd }}$ stroke and serves were placed more in middle zones (especially forehand) compared to unbalanced games. All results are shown in Table 6.

Table 6.

Results of analysis of serve activities for different type of game

Balanced

Unbalanced Very unbalanced

\begin{tabular}{llcccccc} 
& & Frequency & $\%$ & Frequency & $\%$ & Frequency & $\%$ \\
\hline Serve type & FSHOSE & 346 & 74.4 & 634 & 76.9 & 146 & 83.9 \\
& FLONSE & 80 & 18.7 & 154 & 18.9 & 20 & 11.5 \\
& BSHOSE & 32 & 6.9 & 24 & 2.9 & 6 & 3.4 \\
& BLONSE & & & 2 & 1.3 & 2 & 1.1 \\
& Total & 458 & 100.0 & 814 & 100.0 & 174 & 100.0 \\
\hline Won points & SERDIR & 62 & 13.3 & 96 & 11.6 & 12 & 6.9 \\
& SER3WN & 112 & 24.0 & 158 & 19.1 & 58 & 33.3 \\
& SER5WN & 56 & 12.1 & 78 & 9.4 & 26 & 14.9 \\
& SER7WN & 28 & 6.1 & 54 & 6.5 & 8 & 4.6 \\
\cline { 2 - 7 } Lost points & SER3LS & 96 & 20.6 & 236 & 28.6 & 34 & 19.5 \\
& SER5LS & 100 & 21.5 & 192 & 23.2 & 36 & 20.7 \\
& SERROR & 10 & 2.4 & 12 & 1.5 & & \\
& Total & 464 & 100.0 & 826 & 100.0 & 174 & 100.0 \\
\hline Serve placemen & SOUTFH & 54 & 11.9 & 112 & 13.7 & 20 & 11.5 \\
& SMIDFH & 162 & 34.8 & 118 & 15.6 & 26 & 14.9 \\
& SMIDBH & 194 & 41.9 & 434 & 52.5 & 102 & 58.6 \\
& SOUTBH & 48 & 11.4 & 150 & 18.2 & 26 & 14.9 \\
& Total & 458 & 100.0 & 814 & 100.0 & 174 & 100.0 \\
\hline
\end{tabular}

\section{Discussion}

The objective of the research was to analyze serve activities in elite European players. .

Regarding the serve type, the forehand short serve was dominant (around 80\%) and as in some previous research there was a significant difference in the use of the forehand short serve in favour of the winners (Djokic, 2003).
Winners are better at performing short serves than losers. Most points were won (and finished) in the $3^{\text {rd }}$ ball and the rate of points won directly with serves is high $-11.6 \%$, but still lower than before changes of the serve rules were applied - $14.3 \%$ (Djokic, 2003). The same results were found also in a recent study of Djokic et al. (2019).

There was a significant association between winning the match and serve outcome with point directly won with the serve and the winning point after $5^{\text {th }}$ and $7^{\text {th }}$ ball. Zhang et al. (2013) indicated a 
correlation between technique effectiveness and competition performance based exactly on these activities, which illustrates a difference between winners and losers.

In this study, percentage of won serve for the winners was $57.1 \%$, and is in relation with previous researches of the best European players (53.1 $61.6 \%$ ) and best world players (59.3\%) (Djokic, Munivrana, \& Levajac, 2016a, 2016b, 2017).

The most used zone on the opponent's side of the table where the serve were placed was middle, but more towards the backhand side, so players' placement decisions are more or less the same as before (Djokic, 2003).

Analyzing serve type and outcome instead of the phase of the game, we found that as the game goes on in the second and third phases players start performing backhand serves as an alternative serve (because neither player hadn't use a backhand serve in first phase of game). In the third phase, points were more often won with $3^{\text {rd }}$ or $5^{\text {th }}$ stroke, so, in this phase the server must have a high level of concentration on quality realization in short rallies.

A significant association between phase of the match and serve type was noticed, in fact, that the backhand, serve was in use in the $2^{\text {nd }}$ and $3^{\text {rd }}$ phase (not in $1^{\text {st }}$ phase), probably as a choice by players to change something in the game. In addition, in the last phase, all players were trying to play a short serve in which game points usually were decided after $5^{\text {th }}$ stroke.

Most of the points after the serve were won on the $3^{\text {rd }}$ and $5^{\text {th }}$ stroke $(65.2 \%)$, which is higher than that reported in some previous research reported in European Championships (46.5\%) and World Championships final (50\%) (Djokic, Munivrana, \& Levajac, 2016a, 2016b).

In balanced games, the backhand short serve was more frequently used, probably as a player's attempt to change something and disturb the receiving opponent. Furthermore, in such matches there were more points won directly with the serve, and points won with $3^{\text {rd }}$ stroke rather than in unbalanced ones. Accordingly, even if several table tennis rules intentionally reduced the advantage of the server
(Djokic et al., 2019), the players do have the ability to make multiple types of services with identical motions, and so the service still has an important impact on a rally.

\section{Conclusions}

The results of the present study indicate that the quality of serve activities is an important differentiator between winners and losers in table tennis. The results of this research can be useful for coaches and players with regard to the identification of important aspects of serve activities, in order to design better training sessions. In addition, the findings can be seen as an advertisement for a particular model of performance analysis indicating a need for continuous systematic match observation in this sport.

\section{References}

Djokic, Z. (2002a). Differences caused with new $40 \mathrm{~mm}$ ball in structure of competitors' activities of top table tennis players. International Journal of Table Tennis Sciences, 5, 220-232.

Djokic, Z. (2002b). Structure of competitors' activities of top table tennis players. International Journal of Table Tennis Sciences, 5, 74-90.

Djokic, Z. (2003). Service and service return in modern top table tennis. Book of abstracts of the $8^{\text {th }}$ International Table Tennis Federation Sports Science Congress - The $3^{\text {rd }}$ World Congress of Science and Racket Sports (p.21). Lausanne: ITTF.

Djokic, Z., Munivrana, G., \& Levajac, D. (2016a). Match analyses of the final game of Men's World Championship 2014 - China vs. Germany. In Kondrič. M., Zhang, X. \& Xiao D. (Eds.), Science and Racket Sports V (p. 242-250). Suzhou University Press, China: Soochow University \& International Table Tennis Federation

Djokic, Z., Munivrana, G., \& Levajac, D. (2016b). Match analyses of final game of Men's Team European Championships 2014 - Portugal vs. Germany. In Kondrič. M., Zhang, X. \& Xiao D. (Eds.) Science and Racket Sports V. (p. 113-121). Suzhou 
University Press, China: Soochow University \& International Table Tennis Federation.

Djokic, Z., Munivrana, G., \& Levajac, D. (2017). Role of serve and return of serve at European Games 2015 table tennis tournament. In Kondrič, M., Fuchs, M. \& Matjašič, T. (Eds.), Proceedings book of the $15^{\text {th }}$ ITTF Sports Science Congress (p. 242-246). Switzerland: International Table Tennis Federation.

Djokic, Z., Straub, G., Malagoli Lanzoni, I., Katsikadelis, M., \& Munivrana, G. (2019). Effects of rule changes on performance efficacy: Differences between winners and losers table tennis players. Facta universitatis - series: Physical Education and Sport, 17(1).

Fuchs, M., Liu, R., Malagoli Lanzoni, I., Munivrana, G., Straub, G., Tamaki, S., Yoshida, K., Zhang, H., \& Lames, M. (2018). Table tennis match analysis: a review. J Sports Sci, 36(23), 2653-2662.

Geske, K.M., \& Muller, J. (2010). Table tennis tactics (p. 71-77). Aachen: Meyer \& Meyer Sport.

Hughes, M., Cooper, S.M., \& Nevill, A. (2004). Analysis of notation data: reliability. In Hughes, M. \& Franks, M.I. (Eds.), Notational Analysis of Sport-Systems for better coaching and performance in sport (pp.189 204). Second Edition, London: Routledge.

Katsikadelis, M., Pilianidis, T., \& Mantzouranis, N. (2013). The interaction between serves and match winning in table tennis players in the London 2012 Olympic Games. Book of abstracts of the $8^{\text {th }}$ International Table Tennis Federation Sports Science Congress - The $3^{\text {rd }}$ World Congress of Science and Racket Sports (p.77-79). Paris: France.

Krippendorff, K. (2004). Content's analysis: An introduction to its methodology. Thousand Oaks, CA: Sage.

Leite, J. V., Barbieri, F. A., Miyagi, W., Malta, E. S., \& Zagatto, A. M. (2017). Influence of Game Evolution and the Phase of Competition on Temporal Game Structure in High-Level Table Tennis Tournaments. Journal of human kinetics, 55, 55-63.
Malagoli Lanzoni, I., Di Michele, R., \& Merni, F. (2014). A notational analysis of shot characteristics in top-level table tennis players. European Journal of Sport Science, 14(4), 309-317.

McAfee, R. (2009). Table tennis: steps to success. Champaign, Ill.: Human Kinetics.

Molodzoff, P. (2008). ITTF Advanced Coaching Manual (p. 105 - 107). Lausanne: International Table Tennis Federation.

O'Donoghue, P. (2004). Match analysis in racket sports. In A. Lees, J. F. Kahn \& I. W. Maynard (Eds.), Science and Racket Sports III (p. 155 - 162). London: Routledge.

O'Donoghue, P., \& Mayes, A. (2013), Performance analysis, feedback and communication in coaching. In McGarry,T., O'Donoghue, P. and Sampaio, J. (Eds.), Routledge Handbook of Sport Performance Analysis (p.155 - 164). London: Routledge.

Padulo, J., Pizzolato, F., Tosi Rodrigues, S., Migliaccio, G.M., Attene, G., Curcio, R., \& Zagatto, A.M. (2016). Task complexity reveals expertise of table tennis players. Journal of Sports Medicine and Physical Fitness, 56(1-2),149-56.

Tamaki, S., Yoshida, K., \& Yamada, K. (2017). A Shot Number Based Approach to Performance Analysis in Table Tennis. Journal of human kinetics, 55, 7-18.

Tepper, G. (2003). ITTF Level 1 coaching manual. Shanghai Minsun Packaging \& Printing Company: ITTF.

Zhang, H., Liu, W., Hu, J.J., \& Liu, R.Z. (2013). Evaluation of Elite Table Tennis Players' Technique Effectiveness. J Sports Sci, 32(1), 70-77.

Zhang, H., Zhou, Z., \& Yang Q. (2018). Match analyses of table tennis in China: a systematic review. Journal of Sports Science, 36(23), 2663-2674. 